\title{
PENGGUNAAN APLIKASI MEDIA RAKYAT BERBASIS BAHASA DAERAH DI KABUPATEN OGAN ILIR DALAM PENGAWASAN BADAN LEMBAGA NEGARA UNTUK MEMBERANTAS HOAX DI INDONESIA
}

\author{
Aji Teguh Nurseha \\ Universitas Sriwijaya \\ Email: aji.teguh1997@gmail.com \\ Restu Alamsyah \\ Universitas Sriwijaya \\ Email: restualamsyah72@gmail.com \\ Felisa \\ Universitas Sriwijaya \\ Email: felisa221298@gmail.com
}

\begin{abstract}
Abstrak
Hoax menurut KBBI adalah berita bohong yang tidak bersumber yang biasanya disebarkan dari media sosial. Hoax dapat menimbulkan perpecahan dalam masyarakat. Penelitian ini menggunakan pendekatan kualitatif dan rancangan kajian studi pustaka. Dengan adannya ide kami yang berjudul Media Rakyat Berbasis Bahasa Daerah di Kabupaten Ogan Ilir dalam Pengawasan Badan Lembaga Negara untuk Memberantas Hoax di Indonesia. Untuk mewujudkan pemerintahan yang cermat, transparan, dan pelayanan yang baik. Aplikasi media rakyat sendiri berisi pemberitahuan tentang informasi terkait kebijakan-kebijakan pemerintah dibidang pendidikan, kesehatan, ekonomi, sosial dan budaya. Aplikasi ini juga berfungsi untuk meminimalisir adanya berita hoax yang dapat menyebabkan disintegrasi bangsa, dengan cara menyaring data dengan metode ilmiah sehingga informasi yang disebarkan sesuai dengan fakta.
\end{abstract}

Kata kunci: pengawasan, media sosial, dan kebijakan.

Abstract

Indonesia is in an emergency of deceptive news, a hoax according to KBBI is untrue hoax news that is usually spread from social media. Deception can cause divisions in society. This research uses qualitative and studies literature. With the existence of our idea entitled Language Based Media People in Ogan Ilir Regency in the Supervision of State Institutions to Eradicate Hoax in Indonesia. To realize good governance, transparency and good friendliness. The people's media application itself contains information related to government policies in the fields of education, health, economy, social and culture. This application also serves to minimize the existence of deceptive news that can cause disintegration of the nation, by filtering data with scientific methods so that the information disseminated is in accordance with facts.

Keywords: surveillance, social media, and policy.

Scripta: Jurnal Ilmiah Mahasiswa

Fakultas Ilmu Sosial dan Ilmu Politik

Universitas Bangka Belitung

ISSN: 2656-9809 Vol. 1 No. 2. Desember 2019 


\section{PENDAHULUAN}

Dewasa ini, Indonesia sedang darurat berita hoax. Berasal dari bahasa Inggris yang artinya tipuan, menipu, berita bohong, berita palsu dan kabar burung. Jadi "Hoax" dapat diartikan sebagai ketidakbenaran suatu informasi. Hoax merupakan sebuah pemberitaan palsu yakni sebuah usaha untuk menipu atau mengakali pembaca dan pendengarnya agar mempercayai sesuatu. Biasanya seorang yang menyebarkan berita hoax secara sadar melakukan suatu kebohongan dan menyebarkan informasi yang tidak benar. Sekarang ini Hoax cukup erat kaitanya pada isu politik. Biasanya ini dilakukan untuk menyebarkan rumor agar menguntungkan pihak tertentu. Namun tak jarang hoax ditemukan pada kasuskasus lain. ${ }^{1}$

Pemerintah sudah melakukan berbagai kebijakan atau program untuk memberantas hoax salah satunya bekerjasama dengan Polisi Republik Indonesia dengan membentuk cyber crime. Namun dalam pelaksanaannya, sering terjadi masalah dan kurang efektif dalam memberantas hoax. Dalam sebuah penelitian terbaru yang dilakukan oleh We Are Social dan Hootsuite, terungkap bahwa masyarakat Indonesia sangat gemar menggunakan internet. Tercatat, setidaknya kini ada sekira 132,7 juta masyarakat Indonesia yang aktif di berbagai media sosial, maka dengan adanya aplikasi berbasis media sosial dan mobile yang kami ciptakan ini sekiranya dapat menjadi alat yang dapat meminimalisir bahkan dapat memberantas hoax di Indonesia. Dibutuhkan sarana yang dapat digunakan masyarakat untuk mencari dan mendapatkan berita atau informasi yang benar sesuai fakta langsung dari pemerintahan sehingga tidak menimbulkan polemik di dalam negara. Sarana yang tepat adalah dengan menggunakan sistem jaringan internet berbasis perangkat lunak aplikasi penyampai pesan kepada masyarakat. Dengan tujuan masyarakat dapat mengetahui segala sesuatu tentang sistem pembuatan peraturan dan kebijakan pemerintahan.

Aplikasi MERAK(Media RAKyat) ini adalah aplikasi mobile atau android berbasis bahasa daerah yang bertujuan untuk mengawasi sekaligus memberantas berita atau isu yang ada di pemerintahan dan masyarakat dalam hal ini akan kami kembangkan di kabupaten Ogan Ilir Sumatera Selatan. Di dalam aplikasi ini terdapat fitur-fitur seperti ruang obrolan, pelaporan hoax, komentar dan saran untuk kebijakan pemerintah, dan tentunya berita-berita yang sesuai fakta. Berita-berita yang dimuat dalam aplikasi ini akan

\footnotetext{
${ }^{1}$ http://www.sumberpengertian.co/pengertian-hoax, 01/11/18, 14.30

Scripta: Jurnal Ilmiah Mahasiswa

Fakultas Ilmu Sosial dan Ilmu Politik

Universitas Bangka Belitung

ISSN: 2656-9809 Vol. 1 No. 2. Desember 2019
} 
langsung tersambung ke situs-situs resmi pemerintah sehingga berita-berita yang dibaca oleh pengguna aplikasi ini benar adanya.

Dengan adanya ide aplikasi media rakyat berbasis bahasa daerah di Kabupaten Ogan Ilir diharapkan dapat menjadi wadah penyambung pesan dan/atau informasi dari pemerintah ke masyarakat dan/atau dari masyarakat ke pemerintah terkait dengan kebijakan pemerintah dalam pendidikan, ekonomi, politik, sosial dan budaya agar sesuai dengan fakta di lapangan. Tujuan akhir aplikasi ini adalah meminimalisir berita hoax di Indonesia sesuai dengan harapan dalam memberantas berita hoax.

Tujuan penulisan penelitian ini adalah menjadikan aplikasi media rakyat berbasis bahasa daerah sebagai wadah penyambung lidah dari masyarakat ke pemerintah ataupun dari pemerintah ke masyarakat, sebagai media informasi tentang pendidikan, ekonomi, politik, sosial budaya dan lain-lain agartidak ada lagi penyebaran berita hoax, dapat menyederhanakan birokrasi dan menghemat biaya administrasi terkait tentang pelaporan berita hoax, Mensukseskan program E-Goverment dalam menurut asas transparansi dan akuntabilitas.

\section{METODE PENELITIAN}

Penelitian ini merupakan penelitian kualitatif yang mendeskripsikan kondisi objektif tentang objek yang diteliti, berdasarkan perbedaan karakteristik subyek dan fokus penelitian, maka penelitian ini dirancang dengan menggunakan desain studi multi kasus (multi-case studies) (Guba, 1978; Lincoln \& Guba, 1985). Kehadiran peneliti pada penelitian kualitatif merupakan suatu keharusan karena penelitian jenis ini lebih mengutamakan temuan observasi terhadap berbagai fenomena nyata dan alamiah. Wawancara kepada kepala sekolah/kamad dan guru dilakukan oleh peneliti sendiri dan peneliti bertindak sekaligus sebagai instrumen penentu (key instrument). Jenis data dalam penelitian dalam penelitian ini adalah semua data verbal baik berupa kata-kata, ucapan lisan, perilaku subjek (informan) yang berkaitan dengan prakondisi implementasi kebijakan peningkatan kompetensi guru, dan data yang bersumber dari dokumen-dokumen, foto-foto, dan benda-benda yang dapat digunakan sebagai penguat argumentasi. Peneliti-an ini menggunakan rancangan studi multi kasus dengan unit analisis kelompok, yaitu kepada mahasiswa dan warga sekitaran kabupaten Ogan Ilir. Teknik sampling yang digunakan 
dalam penelitian ini melalui dua pentahapan, yaitu: (1) studi kasus tunggal pada kasus pertama digunakan teknik sampling secara purposif yaitu mencari informan kunci (key informan) yang dapat memberi informasi kepada peneliti tentang data yang dibutuhkan; (2) cara pengambilan sampel seperti pada kasus pertama digunakan pula untuk memperoleh data pada kasus kedua. Melalui teknik purposif akhirnya ditetapkan sampel yang menjadi informan kunci sebagai sumber data adalah kepala dinas komunikasi dan informatika kabupaten Ogan Ilir, masyarakat kabupaten Ogan Ilir serta Mahasiswa Universitas Sriwijaya. Berdasarkan informan kunci tersebut selanjutnya dikembangkan untuk mencari informan lainnya dengan teknik bola salju (snowball sampling). Untuk memperoleh data secara holistik dan integratif, serta memperhatikan relevansi data dengan fokus dan tujuan, maka dalam pengumpulan data penelitian ini digunakan tiga teknik, yaitu: wawancara mendalam (indepth interviewing), observasi partisipan (participant observation), dan studi dokumentasi (study of documents) (Bogdan \& Biklen, 1982).

\section{HASIL DAN PEMBAHASAN}

Aplikasi media rakyat merupakan aplikasi yang digunakan untuk melakukan monitoring atau pengawasan terhadap kinerja pemerintahan yang ada di Indonesia, agar rakyat tau bagaimana kinerja dan perkembangan pemerintahan tersebut.

1. Yang pertama dilakukan adalah mendownload aplikasinya di store hp masingmasing, setelah itu buka aplikasinya, berikut ilustrasi logo aplikasi:

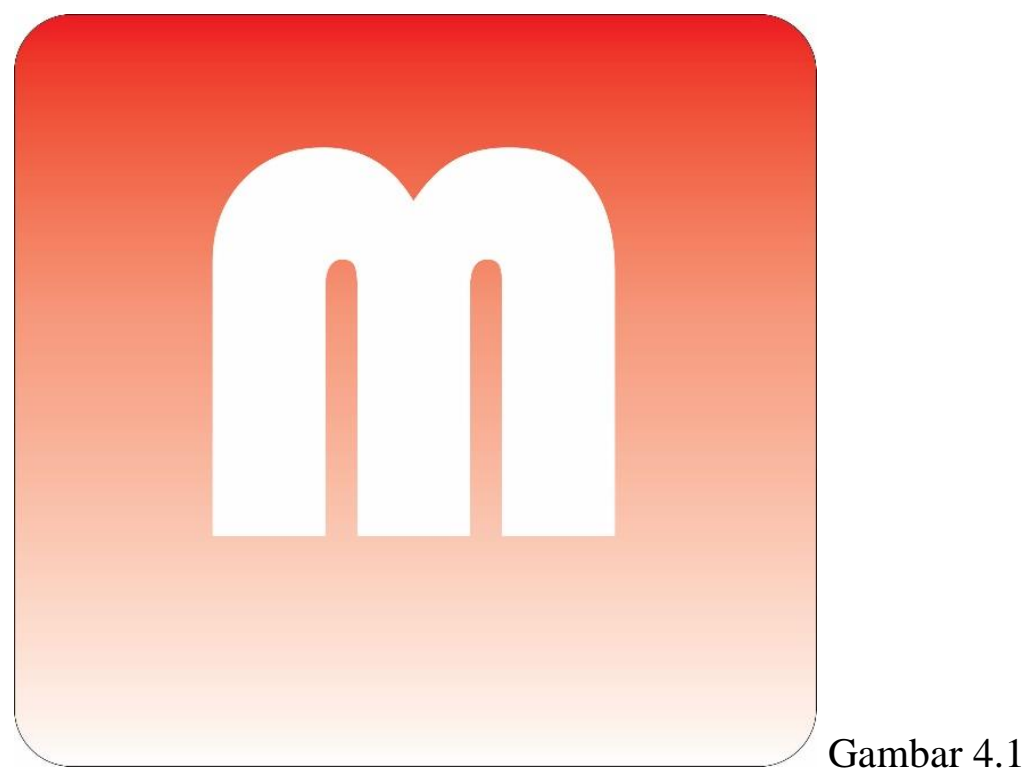

Scripta: Jurnal Ilmiah Mahasiswa

Fakultas Ilmu Sosial dan Ilmu Politik

Universitas Bangka Belitung

ISSN: 2656-9809 Vol. 1 No. 2. Desember 2019 
2. Tampilan awal aplikasi,

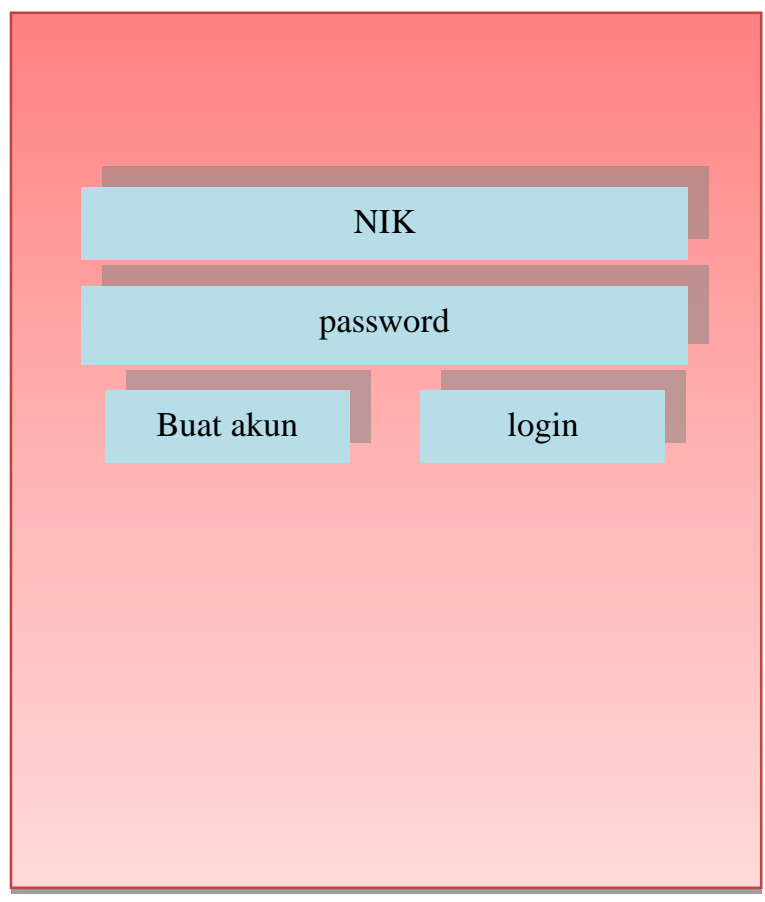

Gambar 4.2

3. Bagi yang belum mendaftar sebelumnya, silahkan buat akun terlebih dahulu

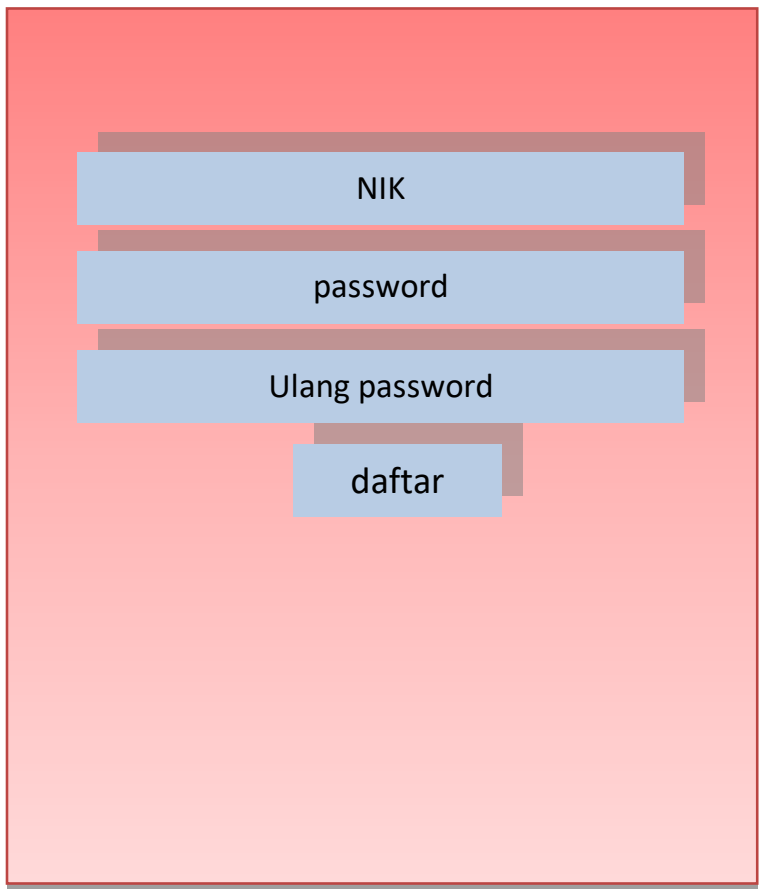

Gambar 4.3

Scripta : Jurnal Ilmiah Mahasiswa

Fakultas Ilmu Sosial dan Ilmu Politik

Universitas Bangka Belitung

ISSN: 2656-9809 Vol. 1 No. 2. Desember 2019 
4. Tampilan beranda aplikasi

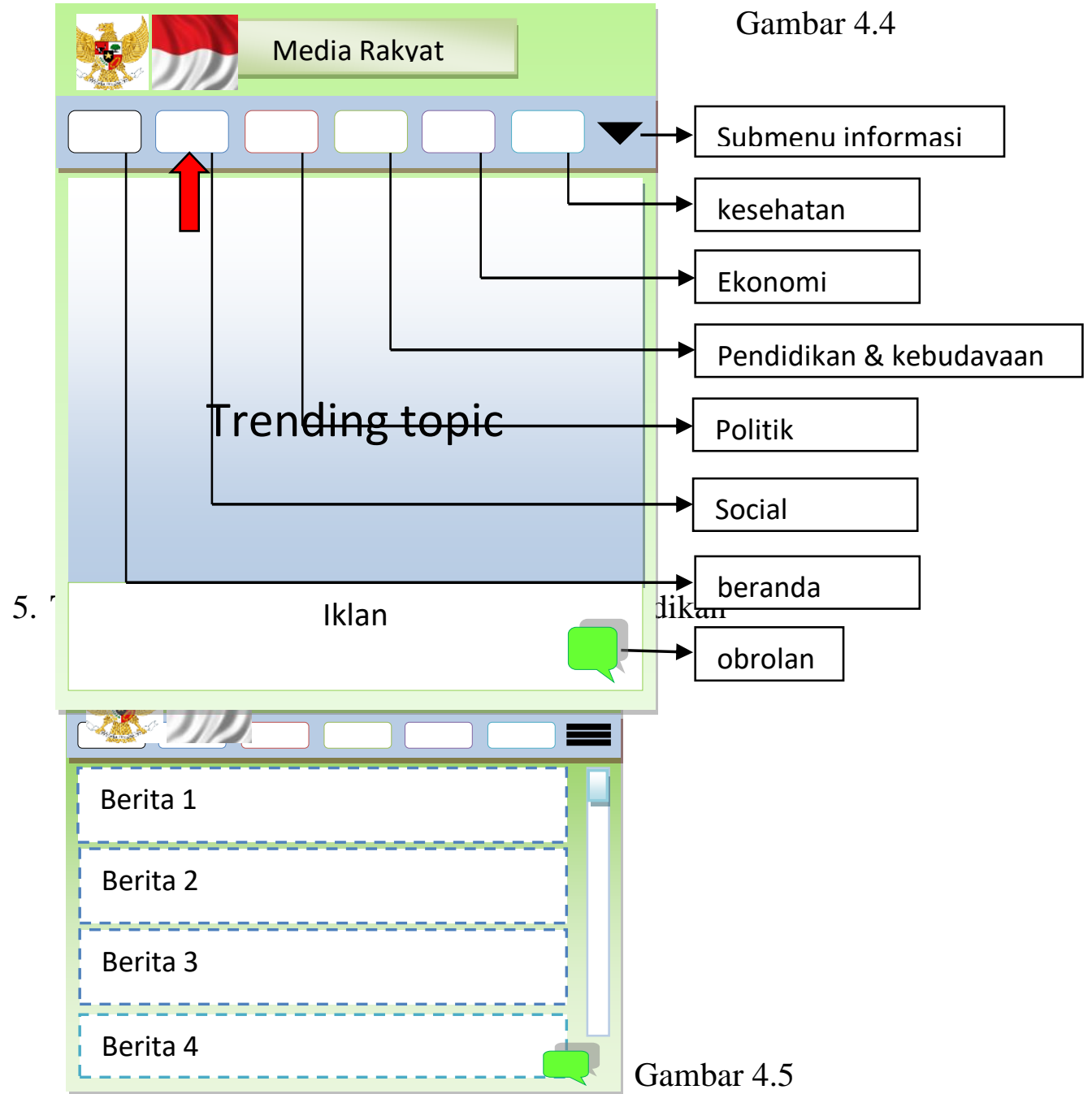

6. Tampilan aplikasi ketika kita meng-klik salah satu berita.

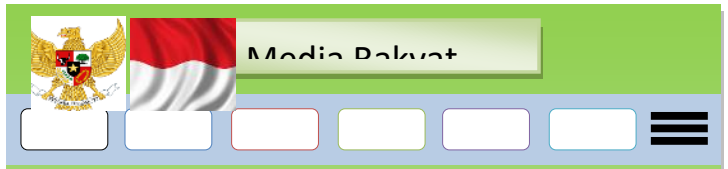

Isi berita ...

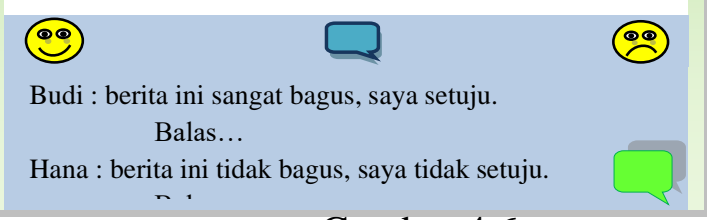

Gambar 4.6

Scripta: Jurnal Ilmiah Mahasiswa

Fakultas Ilmu Sosial dan Ilmu Politik

Universitas Bangka Belitung

ISSN: 2656-9809 Vol. 1 No. 2. Desember 2019 
7. Tampilan apabila kita meng-klik icon submenu informasi.

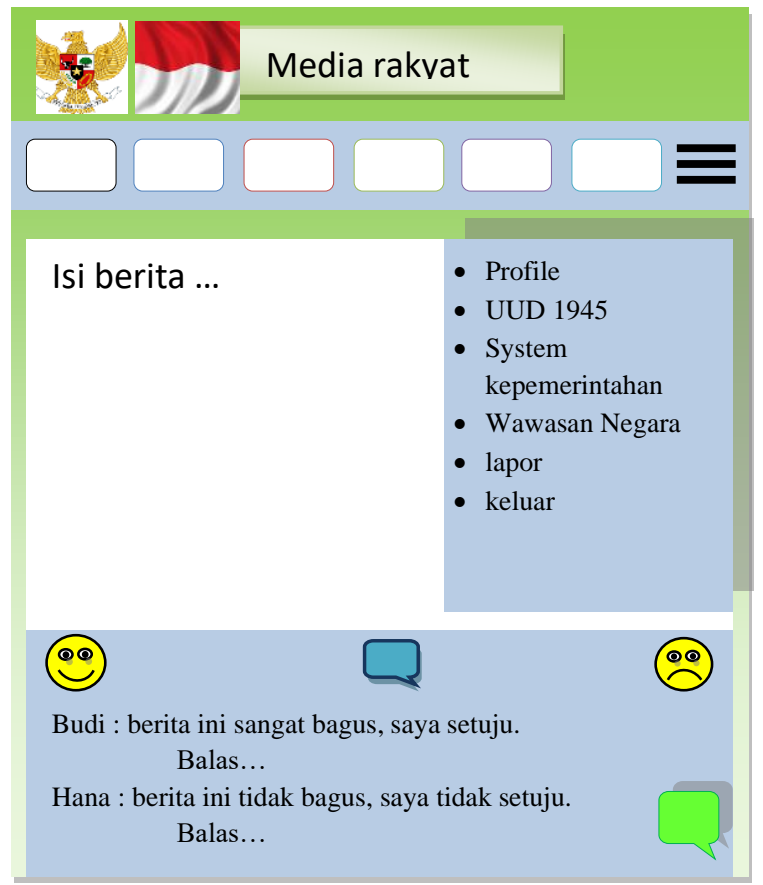

Gambar 4.7

8. Tampilan saat meng-klik icon obrolan

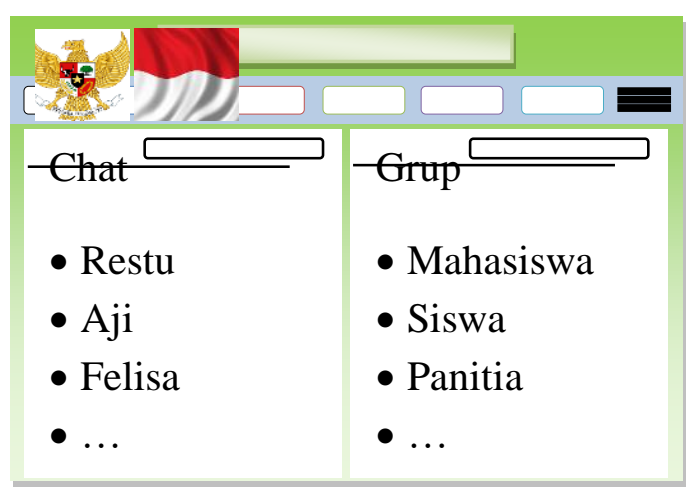

Gambar 4.8

9. Tampilan untuk menu profile

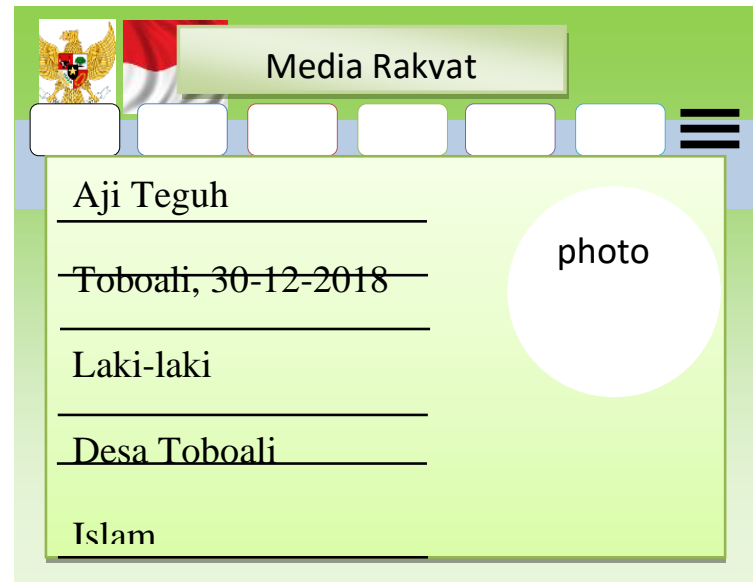

Gambar 4.9

Scripta : Jurnal Ilmiah Mahasiswa Fakultas Ilmu Sosial dan Ilmu Politik Universitas Bangka Belitung

ISSN: 2656-9809 Vol. 1 No. 2. Desember 2019 
10. Tampilan untuk Pelaporan

Kepada : Daftar link tujuan
Alamat : blok H persada
Format laporan
barang bukti :

Gambar 4.10

11. Tampilan untuk Voting peraturan daerah Kabupaten Ogan Ilir

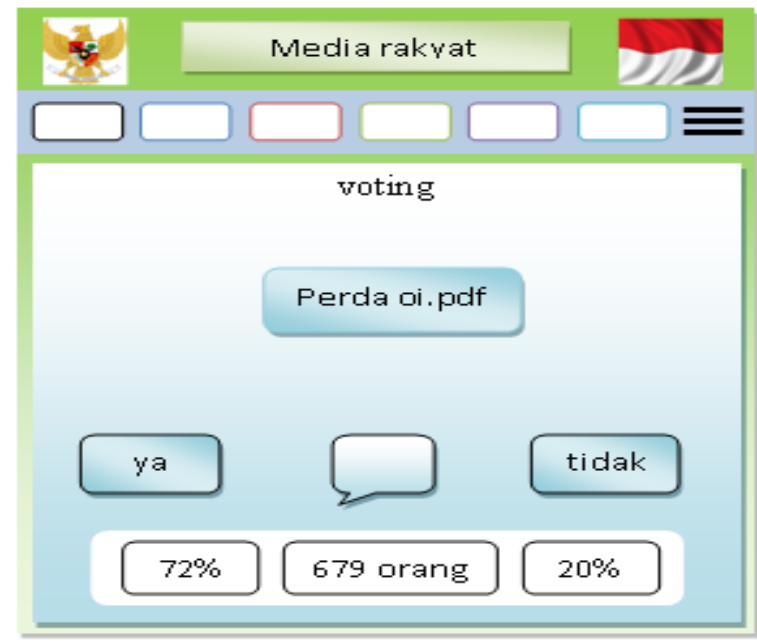

\section{Manfaat Aplikasi Media Rakyat bagi Rakyat dan Pemerintah}

Dari aplikasi ini rakyat bisa mendapatkan informasi yang akurat dari pemerintahan langsung (tanpa ada unsur hoax) dan rakyat juga bisa memantau, menilai kinerja dari pemerintah kabupeten Ogan Ilir Sumatera Selatan. Dan manfaat untuk pemerintah, pemerintah dapat lebih meningkatkan kinerjanya dalam mengelola negara , karena mereka langsung terpantau oleh rakyatnya. Penggunaan bahasa daerah dalam aplikasi ini diharapkan dapat membantu masyarakat dalam memahami term-term atau istilah pemerintahan dengan lebih mudah supaya tidak terdapat kesalahpahaman dan salah mendefinisikan suatu isu atau masalah 
Aplikasi ini juga diharapkan dapat menyederhanakan birokrasi dan menghemat biaya administrasi yang selama ini menjadi masalah atau kendala tersendiri bagi masyarakat yang ingin menyuarakan aspirasi atau sekedar melaporkan hal yang tidak beres di pemerintahan. Jadi dengan adanya aplikasi media rakyat ini, hubungan antara pemerintah dan rakyatnya lebih transparan demi terwujudnya hubungan harmonis antara pemerintah dan rakyatnya.

\section{KESIMPULAN DAN SARAN}

\section{Kesimpulan}

1. Dengan adanya metode pengumpulan data yang berbasis jurnal-jurnal, buku-buku dan berita sehingga aplikasi media rakyat sangat sesuai dengan kebutuhan masyarakat di generasi 4.0

2. Dengan adanya aplikasi media rakyat, dapat mewadahi masyarakat atau pemerintah dapat lebih transparan dalam melakukan dan membuat kebijakan dan peraturan yang sesuai dengan asas transparansi dan akuntabilitas.

3. Dapat menyambung silaturahmi kepada setiap pengguna aplikasi media rakyat.

4. Dengan adanya aplikasi dapat menjadi sumber informasi dan edukasi bagi masyarakat untuk mengetahui ilmu tentang ketatanegaraan.

5. Sebagai wadah untuk pelaporan jika terjadi isu hoax dimasyarakat.

6. Aplikasi ini dapat memangkas birokrasi dan menghemat biaya administrasi yang selama ini mungkin menjadi kendala tersendiri bagi orang-orang yang ingin melapor atau menyuarakan aspirasi namun terkendala pada proses-proses yang akan dilalui.

7. Sebagai media hiburan yang menambah wawasan kenegaraan dan pemerintahan.

8. Sebagai wadah pertimbangan untuk membuat kebijakan bagi pemerintah.

\section{Saran}

- Dengan adanya aplikasi ini, Diharapkan semua masyarakat dapat menggunakan aplikasi ini untuk memudahkan dalam mencari informasi tentang kebijakan pemerintah, pelaporan hoax.

- Pemerintah seharusnya mendukung aplikasi ini dan mengembangkannya bersama kementrian komunikasi dan informasi

Scripta : Jurnal Ilmiah Mahasiswa

Fakultas Ilmu Sosial dan Ilmu Politik

Universitas Bangka Belitung

ISSN: 2656-9809 Vol. 1 No. 2. Desember 2019 
- Dengan adanya aplikasi ini, pemerintah dan masyarakat bijak dalam menanggapi sebuah berita dan tidak terpengaruh dengan berita hoax

- Dengan adanya aplikasi ini, lembaga pemerintahan atau badan masyarakat dapat bekerjasama untuk mewujudkan terbentuknya aplikasi ini lebih baik lagi

- Bagi semua kalangan yang sudah mengetahui tentang aplikasi ini, diharapkan dapat mensosialisasikan aplikasi tersebut agar dapat bermanfaat untuk orang banyak.

\section{DAFTAR PUSAKA}

Asshiddiqie,Jimly. 2009. Pengantar Ilmu Hukum Tata Negara. Rajagrafindo Persada: Bandung .

Abdurrahman , 2012. Metode Penelitian hukum. .Rineka Cipta , Peter Muhamad murzuki: Jakarta.

Araf, Al dan Abbas, Anton Ali et.al. .2008.TNI-POLRI di Masa Perubahan Politik, Program Magister Studi Pertahanan Institut Teknologi Bandung: Bandung.

Baylis, John dan Smith, Steve. 2001 .The Globalization of World Politics. An Introduction to International Relations, Oxford University Press : Surabaya

Budyatna, Muhammad. 2006, Jurnalistik Teori Dan Praktek. Rosda :Bandung.

Djamal, R.abdoel.2012. Pengantar Hukum Indonesia. RajaGrafindo Persada : Jakarta.

Jurna , PERAN MEDIA MASSA DALAM MENINGKATKAN KUALITAS KEPEMERINTAHAN LOKAL BERBASIS HUMAN SECURITY DI KOTAJakarta . Aria Aditya Setiawan.

Mahfud, Mohamad. 2011. Perdebatan Hukum Tata Negara Pasca Amandemen Konsitusi. Raja Grafindo Persada: Jakarta.

Thoha, Miftah. 2008. Ilmu Administrasi Publik Kontemporer. Jakarta : Kencana Media neliti.2016. aplikasi mobile kamus istilah komputer.

https://media.neliti.com/media/publications/231600-aplikasi-mobile-kamus-istilahkomputer-b-976a2be9.pdf, Diakses tanggal 10 Oktober 2018, pukul 13:35

We Are Sosial, 2018, DIGITAL IN 2018: WORLD'S INTERNET USERS PASS THE 4 BILLION MARK.https://wearesocial.com/blog/2018/01/global-digital-report-2018, diakses tanggal 8 April 2018

Scripta: Jurnal Ilmiah Mahasiswa

Fakultas Ilmu Sosial dan Ilmu Politik

Universitas Bangka Belitung

ISSN: 2656-9809 Vol. 1 No. 2. Desember 2019 